\title{
A RECUSA DE TRANSFUSÃO DE SANGUE POR PACIENTE ADEPTO DA RELIGIÃO TESTEMUNHAS DE JEOVÁ: COLISÃO DE DIREITOS FUNDAMENTAIS - ESTUDO DE CASO
}

\section{THE REFUSAL OF BLOOD TRANSFUSION PER PATIENT ADHERENT OF THE RELIGION OF JEHOVAH'S WITNESSES: COLLISION FUNDAMENTAL RIGHTS - CASE STUDY}

\author{
${ }^{1}$ Faustus Máximus de Araujo Alvim \\ ${ }^{2}$ Carlos Alberto Simões de Tomaz
}

\begin{abstract}
RESUMO
O objetivo deste estudo de caso é analisar o tema sob o prisma da colisão entre os direitos fundamentais à vida e à liberdade de consciência e de crença, bem como a sua ponderação, na perspectiva de Robert Alexy. O artigo ampara-se em pesquisa bibliográfica e numa abordagem crítico-dedutiva para verificar que a ponderação dos princípios deve ser determinada através da análise das circunstâncias do caso concreto, fundamentado com os argumentos racionais de convicção. Em conclusão, se aposta numa resposta corretamente justificada a partir do contexto sócio-cultural como o caminho para que se chegue a uma adequada ponderação de princípios.
\end{abstract}

Palavras-chave: Colisão de princípios; ponderação; direito à vida; liberdade de crença.

\begin{abstract}
The objective of this study is to analyze the issue from the perspective of the collision between the fundamental rights to life and freedom of conscience and belief, as well as their weighting in view of Robert Alexy. The article seek refuge in literature and a critical- deductive approach to verify that the balance of principles should be determined by analyzing the circumstances of the case, based on the rational arguments of conviction. In conclusion, if you bet on a properly justified response from the socio- cultural context and the way in order to reach a proper consideration of principles.
\end{abstract}

Keywords: Collision principles; weighting; right to life; freedom of religion.

\footnotetext{
${ }^{1}$ Mestrando em Proteção dos Direitos Fundamentais pela Universidade de Itaúna - UIT, Minas Gerais, (Brasil). Especialista em Direito Processual. Professor na Faculdade ASA de Brumadinho, e na Academia de Polícia Militar de Minas Gerais. Advogado. E-mail: faustusalvim@ hotmail.com

${ }^{2}$ Pós-doutor em Filosofia do Direito pela Universidade de Coimbra, (Portugal). Professor do PPGD - Mestrado em Proteção dos Direitos Fundamentais na Universidade de Itaúna - UIT, Minas Gerais, (Brasil). E-mail: ca.tomaz@uol.com.br
} 


\section{INTRODUÇÃO}

A Constituição da República de 1988, no seu artigo 5º caput, assegura, a todos, como direito e garantia fundamental, à inviolabilidade do direito à vida. Já o inciso VI, deste mesmo diploma constitucional, consagra a inviolabilidade da liberdade de consciência e de crença. Ainda, o artigo $1^{\circ}$, inciso III, da Carta Magna, dispõe como um dos princípios fundamentais a dignidade da pessoa humana. (BRASIL, 2013).

Neste contexto, os seguidores da religião Testemunhas de Jeová, com cerca de oito milhões de praticantes em 240 países, baseados na interpretação que fazem de algumas passagens bíblicas, se recusam a submeter a tratamentos médicos ou cirúrgicos que incluam a transfusão de sangue, mesmo que isso possa leva-los à morte. (JW.ORG, 2015).

O tema desperta interesse, pois envolve a aplicabilidade do direito fundamental à vida em colisão com a liberdade de consciência e de crença (quando a Testemunha de Jeová necessita de transfusão de sangue) e a colisão entre a liberdade de consciência e de crença e a dignidade da pessoa humana (quando há exclusão da testemunha de Jeová que fez a transfusão de sangue), dentro do contexto sócio, cultural e de crença religiosa.

O presente estudo tem como objetivo analisar a recusa de transfusão de sangue por paciente adepto da religião "Testemunhas de Jeová”, sob o prisma da colisão de princípios e sua ponderação, na perspectiva de Robert Alexy. A partir do momento em que os princípios, assim como as regras, são aceitos como espécies do gênero "norma", surge um problema: o que fazer quando dois direitos fundamentais colidem?

Esta pesquisa se justifica pela atualidade do tema e sua repercussão, pois envolve no mundo cerca de oito milhões de adeptos da religião Testemunhas de Jeová e pela sua pertinência com o estudo da Teoria dos Direitos Fundamentais.

Através de estudo do caso da menina Juliana Bomfim da Silva, de São Vicente/São Paulo, pretende-se analisar o resultado da trajetória processual que se arrastou por mais de duas décadas, o que motivou a escolha deste caso para a realização deste trabalho científico.

A menor Juliana (Testemunha de Jeová) faleceu em 22.07.1993, devido à recusa, pelos seus pais, de realizar transfusão de sangue. Foi aberto Inquérito Policial que resultou em uma ação penal, tendo como réus os pais da menina. Em 02.09.2014, ocorreu o julgamento final do Habeas Corpus (n $\mathrm{n}^{\mathrm{o}}$ 268.459-SP) pelo Superior Tribunal de Justiça, que, em razão do empate, 
prevalecendo à decisão mais favorável, concedeu Ordem de Ofício para extinguir a ação penal em relação aos pais da menor. (BRASIL, 2014, p. 1/29).

O presente trabalho ainda será baseado em pesquisa bibliográfica e com uma abordagem crítico-dedutiva pretende apresentar um breve conceito sobre a estrutura das normas de direitos fundamentais, regras e princípios, colisão entre princípios e conflitos entre regras, a lei de colisão e a ponderação de princípios colidentes, na perspectiva de Robert Alexy, Ronald Dworkin e Marcelo Neves, além de identificar a sua eventual inclusão nas decisões proferidas no caso em estudo.

$\mathrm{Na}$ sequencia, será realizada uma análise da colisão dos direitos fundamentais envolvendo o direito à vida, a liberdade de crença e a dignidade da pessoa humana, no caso da menina Juliana Bomfim da Silva e de dois outros casos representativos da jurisprudência.

Por fim, serão apresentadas as considerações finais sobre o estudo realizado, reputando que a ponderação de princípios deve se encontrar atrelada à análise das circunstâncias e especificidades de cada caso concreto, devidamente fundamentada de tal sorte a garantir que o resultado não venha a aniquilar um dos princípios colidentes e revele uma resposta corretamente justificada com atenção ao contexto social e inteiramente voltada para satisfazer a dignidade da pessoa humana.

\section{O CASO DA MENINA JULIANA DE SÃO VICENTE/SÃO PAULO}

Em 21 de julho de 1993, na cidade de São Vicente/São Paulo, litoral paulista, Juliana Bonfim da Silva, 13 anos, foi internada no Hospital São José, devido ao agravamento do seu estado de saúde, pois sofria de Anemia Falciforme. (BRASIL, 2014, p. 1).

Em 22 de julho de 1993, a menina Juliana faleceu no Hospital em consequência de assistolia ventricular, crise vásculo oclusiva e anemia falciforme, em decorrência da baixíssima quantidade de componentes hemáceos que exigia, com urgência, uma transfusão de sangue, que fora recusada pelos pais responsáveis da menor, invocando preceitos da religião "Testemunhas de Jeová”, da qual eram adeptos (BRASIL, 2014, p. 1/2).

Com a morte da menor foi aberto Inquérito Policial que resultou na Denúncia oferecida pelo Ministério Público de São Paulo, que em 22 de julho de 1997 culminou na Ação Penal de Competência do Júri, processo de $n^{\text {o }}$ 0000338-97.1993.8.26.0590, em trâmite na $3^{\mathrm{a}}$ Vara Criminal da Comarca de São Vicente/São Paulo. (BRASIL, 2014, p. 1/2). 
A seguir, será apresentada uma síntese da trajetória processual deste caso, que culminou com o julgamento do Habeas Corpus pelo Superior Tribunal de Justiça.

\subsection{Síntese da trajetória processual do Caso da menina Juliana de São Vicente/São Paulo}

Na Denúncia do caso em estudo, o Ministério Público sustentava que os pais mataram a filha menor por motivos religiosos ao impedir que os médicos do Hospital São José realizassem a necessária transfusão de sangue. (BRASIL, 2014, p. 2).

A Denúncia também envolvia o médico José Augusto Faleiros, amigo da família, que aconselhou os pais da menor a não autorizar a transfusão de sangue e intimidou os médicos que assistiam à paciente, ameaçando processá-los judicialmente caso efetuassem a transfusão de sangue contra a vontade dos pais. (BRASIL, 2014, p. 2).

Em 25.07.1997 foi publicada a sentença de Pronúncia dos pais (Hélio Vitória da Silva e Ildelir Bonfim de Souza) e do médico, amigo da família, José Augusto Faleiros. Os réus interpuseram Recurso em sentido Estrito ( ${ }^{\circ}$ 993.99.085354-0), buscando a anulação da Pronúncia que resultou na Ação Penal de Competência do Júri. (BRASIL, 2014, p. 1/10).

Em 28.01.2010 a $9^{\text {a }}$ Câmara Criminal do Tribunal de Justiça de São Paulo, por maioria de votos, negou provimento ao Recurso e manteve a sentença de Pronúncia, sendo vencido o voto do Desembargador Nuevo Campos Júnior. (BRASIL, 2014, p. 1/10).

Os réus apresentaram Embargos de Declaração ao Acórdão, mas foram rejeitados em 29.04.2010 por voto unânime. Os réus interpuseram Embargos Infringentes, cujo julgamento em 18.11.2010, por maioria de votos, rejeitou o Recurso, sendo vencidos os votos dos Desembargadores Souza Nery e Nuevo Campos. Novos Embargos de Declaração foram manejados pelos réus, mas também rejeitados em 25.08.2011. (BRASIL, 2014, p. 1/10).

Em 22.08.2011, apresentaram Recurso Especial buscando reforma do Acórdão que manteve a sentença de Pronúncia. Em 29.02.2012, o Presidente do Tribunal de Justiça do Estado de São Paulo não admitiu o Recurso Especial. (BRASIL, 2014, p. 1/10).

Em 20.03.2012 os réus interpuseram Agravo em Recurso Especial para o Superior Tribunal de Justiça - STJ, que foi negado em julgamento ocorrido em 14.08.2012. Os réus manejaram Agravo Regimental no Agravo em Recurso Especial, julgado pelo STJ em 11.09.2012, que negou provimento. (BRASIL, 2014, p. 1/10). 
Os réus ainda apresentaram Embargos de Declaração no Agravo Regimental do Agravo em Recurso Especial, que também foi rejeitado pelo STJ no julgamento ocorrido em 09.10.2012. (BRASIL, 2014, p. 1/10).

Em 16.04.2013, o advogado dos pais da menina Juliana protocolizou o Habeas Corpus $\mathrm{n}^{\circ}$ 268.459-SP, distribuído por dependência à $6^{\mathrm{a}}$ Turma do Superior Tribunal de Justiça, para a Ministra Relatora Maria Thereza de Assis Moura. (BRASIL, 2014, p. 11/29).

Em 04.02.2014, iniciou o julgamento com o voto da Ministra Relatora, que, em síntese, não conheceu do Habeas Corpus, expedindo, contudo, a Ordem de Ofício. Houve pedido de vista do Ministro Sebastião Reis Júnior. (BRASIL, 2014, p. 11/29).

Em 12.08.2014, houve a proclamação do voto do Ministro Sebastião Reis Júnior, que, em síntese, também não conheceu do Habeas Corpus, expedindo, todavia, a Ordem de Ofício. Houve pedido de vista do Ministro Rogério Schietti Cruz. (BRASIL, 2014, p. 11/29).

Em 02.09.2014, houve o final do julgamento pela $6^{\mathrm{a}}$ Turma do STJ que, por unanimidade de votos, não conheceu do pedido de Habeas Corpus e, em razão do empate, prevalecendo à decisão mais favorável, concedeu Ordem de Ofício para extinguir a ação penal em relação aos réus, cuja ementa se encontra assim vazada: (BRASIL, 2014, p. 11/29)

PROCESSO PENAL. HABEAS CORPUS. HOMICÍDIO. (1) IMPETRAÇÃO COMO SUCEDÂNEO RECURSAL, APRESENTADA DEPOIS DA INTERPOSIÇÃO DE TODOS OS RECURSOS CABÍVEIS. IMPROPRIEDADE DA VIA ELEITA. (2) QUESTÕES DIVERSAS DAQUELAS JÁ ASSENTADAS EM ARESP E RHC POR ESTA CORTE. PATENTE ILEGALIDADE. RECONHECIMENTO. (3) LIBERDADE RELIGIOSA. ÂMBITO DE EXERCÍCIO. BIOÉTICA E BIODIREITO: PRINCÍPIO DA AUTONOMIA. RELEVÂNCIA DO CONSENTIMENTO ATINENTE À SITUAÇÃO DE RISCO DE VIDA DE ADOLESCENTE. DEVER MÉDICO DE INTERVENÇÃO. ATIPICIDADE DA CONDUTA. RECONHECIMENTO. ORDEM CONCEDIDA DE OFÍCIO.

1. É imperiosa a necessidade de racionalização do emprego do habeas corpus, em prestígio ao âmbito de cognição da garantia constitucional, e, em louvor à lógica do sistema recursal. In casu, foi impetrada indevidamente a ordem depois de interpostos todos os recursos cabíveis, no âmbito infraconstitucional, contra a pronúncia, após ter sido aqui decidido o AResp interposto na mesma causa. Impetração com feições de sucedâneo recursal inominado.

2. Não há ofensa ao quanto assentado por esta Corte, quando da apreciação de agravo em recurso especial e em recurso em habeas corpus, na medida em que são trazidos a debate aspectos distintos dos que outrora cuidados.

3. Na espécie, como já assinalado nos votos vencidos, proferidos na origem, em sede de recurso em sentido estrito e embargos infringentes, tem-se como decisivo, para o desate da responsabilização criminal, a aferição do relevo do consentimento dos pacientes para o advento do resultado tido como delitivo. Em verdade, como inexistem direitos absolutos em nossa ordem constitucional, de igual forma a liberdade religiosa também se sujeita ao concerto axiológico, acomodando-se diante das demais condicionantes valorativas. Desta maneira, no caso em foco, ter-se-ia que 
aquilatar, a fim de bem se equacionar a expressão penal da conduta dos envolvidos, em que medida teria impacto a manifestação de vontade, religiosamente inspirada, dos pacientes. No juízo de ponderação, o peso dos bens jurídicos, de um lado, a vida e o superior interesse do adolescente, que ainda não teria discernimento suficiente (ao menos em termos legais) para deliberar sobre os rumos de seu tratamento médico, sobrepairam sobre, de outro lado, a convicção religiosa dos pais, que teriam se manifestado contrariamente à transfusão de sangue. Nesse panorama, tem-se como inócua a negativa de concordância para a providência terapêutica, agigantando-se, ademais, a omissão do hospital, que, entendendo que seria imperiosa a intervenção, deveria, independentemente de qualquer posição dos pais, ter avançado pelo tratamento que entendiam ser o imprescindível para evitar a morte. Portanto, não há falar em tipicidade da conduta dos pais que, tendo levado sua filha para o hospital, mostrando que com ela se preocupavam, por convicção religiosa, não ofereceram consentimento para transfusão de sangue - pois, tal manifestação era indiferente para os médicos, que, nesse cenário, tinham o dever de salvar a vida. Contudo, os médicos do hospital, crendo que se tratava de medida indispensável para se evitar a morte, não poderiam privar a adolescente de qualquer procedimento, mas, antes, a eles cumpria avançar no cumprimento de seu dever profissional.

4. Ordem não conhecida, expedido habeas corpus de ofício para, reconhecida a atipicidade do comportamento irrogado, extinguir a ação penal em razão da atipicidade do comportamento irrogado aos pacientes. (BRASIL, 2014, p. 11/12).

\subsection{Breves apontamentos sobre as Testemunhas de Jeová}

“Testemunhas de Jeová” é uma denominação cristã, que possui adeptos em 240 países, com cerca de oito milhões de praticantes. São conhecidas pelo seu trabalho regular de pregação de seus princípios de casa em casa, nas ruas e em locais públicos. (JW.ORG, 2015).

Os adeptos desta religião, baseados nos livros da Bíblia cristã (Genesis 9:4; Levíticos 7:14; Atos 15:20 ${ }^{3}$ ) não admitem que ninguém de sua família se submeta à transfusão de sangue em quaisquer tratamentos cirúrgicos e/ou médicos. (JW.ORG, 2015).

Ressalte-se que se uma pessoa "testemunha de Jeová batizada" passa a ter o costume de violar o "código de moral da Bíblia" e não se arrepende, ela é desassociada, ou evitada pelos membros da religião. Esta postura é justificada através da Bíblia, com base em $1^{\circ}$ Coríntios 5:13, que diz: "Removei o homem iníquo de entre vós." (JW.ORG, 2015).

\footnotetext{
3 “Gênesis 9:4. Embora tivesse permitido que Noé e sua família passassem a se alimentar de carne animal após o Dilúvio, Deus os proibiu de comer o sangue. Ele disse a Noé: "Somente a carne com a sua alma — seu sangue — não deveis comer." Desde então, isso se aplica a todos os humanos, porque todos são descendentes de Noé. Levítico 17:14. "Não deveis comer o sangue de qualquer tipo de carne, porque a alma de todo tipo de carne é seu sangue. Quem o comer será decepado da vida.” Para Deus, a alma, ou vida, está no sangue e pertence a Ele. Embora essa lei tenha sido dada apenas à nação de Israel, ela mostra a importância que Deus dava a não comer sangue. Atos 15:20. 'Abstenham-se do sangue.' Deus deu aos cristãos a mesma proibição que deu a Noé. A História mostra que os primeiros cristãos não consumiam sangue, nem mesmo para fins medicinais”. (JW.ORG, 2015).
} 
Em sua revista bimestral "Despertai", edição n 1.2016, os seguidores desta religião ponderam que "não aceitamos tratamentos médicos que entrem em conflito com os princípios bíblicos. Por exemplo, recusamos transfusões de sangue porque a Bíblia diz que não devemos aceitar sangue - Atos 15:20, 28, 29”. (JW.ORG, 2016, p.8).

\section{A ESTRUTURA DAS NORMAS DE DIREITOS FUNDAMENTAIS}

A discussão acerca do conceito de norma como pilar fundamental da ciência do Direito gera muita polêmica, pois envolve discussões sobre o seu objeto e método, ou seja, sobre seu próprio caráter. (ALEXY, 2015, p. 53/57).

Para Nicola Abbagnano (2007, p. 716), o conceito de norma é recente, “cuja origem está no neocriticismo alemão; formou-se através da distinção e da contraposição entre o domínio empírico do fato (da necessidade natural) e o domínio racional do dever ser (da necessidade ideal)".

Para Alexy, norma de direito fundamental constitui o significado extraído de determinado enunciado normativo, podendo ser chamado de "enunciado normativo de direito fundamental" (ALEXY, 2015, p. 66).

Outro ponto importante para a dogmática dos direitos fundamentais "é a definição da relação entre o conceito de direito a algo e os conceitos de dever e de liberdade", baseando-se em três modalidades deônticas básicas, quais sejam: os conceitos de dever (modalidade deôntica de obrigação), de proibição (modalidade deôntica do que é proibido) e de permissão (modalidade deôntica do que é permitido). (ALEXY, 2015, p. 204).

Alexy ainda ressalta que as normas de direito fundamental podem ser divididas em dois grupos: as normas de direito fundamental estabelecidas diretamente pelo texto constitucional e as "normas de direito fundamental atribuídas", as quais são necessárias quando a norma expressa pelo texto constitucional tem que ser aplicada a casos concretos. (ALEXY, 2015, p. 72/73).

Se as "normas de direito fundamental atribuídas" não fossem aceitas não ficaria claro o que é obrigado, proibido ou permitido de acordo com o texto constitucional, isto é, de acordo com a norma por ele diretamente expressa. (ALEXY, 2015, p. 72/73). 


\subsection{Regras e Princípios}

Para Abbagnano (2007, p. 840) regra é “qualquer proposição de natureza prescritiva. Esse termo é generalíssimo e compreende as noções mais limitadas de norma, máxima e lei”.

Kant, citado por Abbagnano (2007, p. 792), entendia por princípio "toda proposição geral, mesmo extraída da experiência por indução, que possa servir de premissa maior num silogismo".

Para Robert Alexy, a análise da estrutura das normas de direitos fundamentais passa, necessariamente, pela distinção entre regras e princípios. "Essa distinção é a base da teoria da fundamentação no âmbito dos direitos fundamentais e uma chave para a solução de problemas centrais da dogmática dos direitos fundamentais". (ALEXY, 2015, p. 85).

A distinção entre regras e princípios é uma distinção entre duas espécies de normas, pois "tanto regras quanto princípios são normas, porque ambos dizem o que deve ser. Ambos podem ser formulados por meio das expressões deônticas básicas do dever, da permissão e de proibição". (ALEXY, 2015, p. 87).

Os princípios são normas que ordenam que algo seja realizado na maior medida possível, dentro das possibilidades jurídicas e fáticas existentes, ou seja, "são mandamentos de otimização que são caracterizados por poderem ser satisfeitos em graus variados e pelo fato de que a medida devida de sua satisfação não depende somente das possibilidades fáticas, mas também das possibilidades jurídicas". (ALEXY, 2015, p, 90).

As regras "são normas que são sempre ou satisfeitas ou não satisfeitas. Se uma regra vale, então, deve se fazer exatamente aquilo que ela exige; nem mais, nem menos. Regras contêm, portanto, determinações no âmbito daquilo que é fática e juridicamente possível”. (ALEXY, 2015, p. 91).

Robert Alexy (1988, p. 144), ressalta em sua obra 'Sistema jurídico, principios jurídicos y razón práctica' que "hay por tanto distintos grados de cumplimiento. Si se exige la mayor medida posible de cumplimiento em relación com las possibilidades jurídicas y fácticas, se trata de um principio. Si sólo se exige uma determinada medida de cumplimiento, se trata de uma regla".

Ronald Dworkin denomina 'princípio' como sendo “um padrão que deve ser observado, não porque vá promover ou assegurar uma situação econômica, política ou social 
considerada desejável, mas porque é uma exigência de justiça ou equidade ou alguma outra dimensão da moralidade". (DWORKIN, 2002, p. 36).

Para Dworkin (2002, p.39), “a diferença entre princípios jurídicos e regras jurídicas é de natureza lógica. Os dois conjuntos de padrões apontam para decisões particulares acerca de obrigação jurídica em circunstâncias específicas, mas distinguem-se quanto à natureza da orientação que oferecem”. Para ele, “as regras são aplicáveis à maneira do tudo-ou-nada. Dados os fatos que uma regra estipula, ou a regra é valida, e neste caso a resposta que ela fornece deve ser aceita, ou não é válida, e neste caso em nada contribui para a decisão”. Já os princípios “possuem uma dimensão que as regras não têm - a dimensão do peso ou importância. Quando os princípios se intercruzam, aquele que vai resolver o conflito tem de levar em conta a força relativa de cada um para a solução do caso". (Dworkin, 2002, p. 42).

Dworkin sustenta que "às vezes, regras ou princípios podem desempenhar papéis bastante semelhantes e a diferença entre eles reduz-se quase a uma questão de forma". (DWORKIN, 2002, p. 44). E ainda que, “se entendermos por 'princípio de direito' um princípio que pode, por princípio, ser escolhido para esse papel, então todos os princípios de moralidade política vigentes na comunidade em questão são princípios jurídicos”. (DWORKIN, 2002, p. 527).

Segundo Marcelo Neves (2013, p. 103) “os princípios são normas no plano reflexivo, possibilitando o balizamento e a construção ou reconstrução de regras. Estas, enquanto razões imediatas para normas de decisão, são condições da aplicação dos princípios à solução dos casos".

Para Alexy (2015, p. 90), os princípios são “mandamentos de otimização” que podem ser satisfeitos em graus variados e que a "medida de sua satisfação" não depende somente das possibilidades fáticas, mas também das possibilidades jurídicas, enquanto que "as regras são normas que são sempre ou satisfeitas ou não satisfeitas". Assim, "se uma regra vale, deve se fazer exatamente aquilo que ela exige; nem mais, nem menos. Isto significa que a distinção entre regras e princípios é uma distinção qualitativa e não uma distinção de grau”. (ALEXY, 2015, p. 91).

Entende Alexy que a diferença entre regras e princípios mostra-se com maior clareza nos casos de colisões entre princípios e de conflitos entre regras. "Comum às colisões entre princípios e aos conflitos entre regras é o fato de que duas normas, se isoladamente aplicadas, levariam a resultados inconciliáveis entre si, ou seja, a dois juízos concretos de dever-ser 
jurídico contraditório. E elas se distinguem pela forma de solução do conflito". (ALEXY, 2015, p. 91/92).

\title{
3.2 Colisão entre Princípios e Conflitos entre Regras
}

Para Alexy (2015, p. 92), "um conflito entre regras somente pode ser solucionado se se introduz, em uma das regras, uma cláusula de exceção que elimine o conflito, ou se pelo menos uma das regras for declarada inválida". Para ilustrar o autor apresenta o seguinte caso:

\begin{abstract}
Um exemplo para um conflito entre regras que pode ser resolvido por meio da introdução de uma cláusula de exceção é aquele entre a proibição de sair da sala de aula antes que o sinal toque e o dever de deixar a sala se soar o alarme de incêndio. Se o sinal ainda não tiver sido tocado, mas o alarme de incêndio tiver soado, essas regras conduzem a juízos concretos de dever-ser contraditórios entre si. (ALEXY, 2015, p. 92).
\end{abstract}

Alexy ressalta que "a colisão entre princípios deve ser solucionada de forma diversa. Assim, se dois princípios colidem, um dos princípios terá que ceder, pois haverá precedência de um princípio em face do outro, sob determinadas condições”. (ALEXY, 2015, p. 93).

Marcelo Neves (2013, p. 84), aduz que, no modelo de Alexy, os princípios enquanto “critérios prima facie, servem de fundamento mediato de decisões de controvérsias jurídicas, as regras, além do caráter prima facie no ponto de partida de um processo concretizador, só desempenham sua função plena, quando, no final desse processo, transmudam-se em razão definitiva".

Para Marcelo Neves, nos casos não rotineiros, o direito se flexibiliza mediante princípios constitucionais para possibilitar uma maior adequação da argumentação jurídica à complexidade da sociedade. (NEVES, 2013, p. 57/58).

Quanto às regras, "embora pouco flexíveis para enfrentar as expectativas mais contraditórias em relação aos direitos e deveres constitucionais, reduzem a complexidade dos princípios, possibilitando a passagem de um estado de incerteza inicial para a certeza no final do procedimento de solução do caso”. (NEVES, 2013, p. 58).

Para Marcelo Neves (2013, p. 95), “a distinção entre princípios e regras como categorias de normas torna-se relevante só quando surge a controvérsia sobre a norma a aplicar ao caso, no contexto de um conflito interpessoal concreto ou no âmbito de um controle abstrato de normas". 


\subsection{A Lei de Colisão}

Para Alexy, se um princípio restringe as possibilidades jurídicas de realização de outro, esta situação não será resolvida com a declaração de invalidade de um dos princípios e com sua eliminação do ordenamento jurídico. Segundo esse autor, "a solução para essa colisão consiste no estabelecimento de uma relação de precedência condicionada entre os princípios, com base nas circunstâncias do caso concreto”. (ALEXY, 2015, p. 96).

Assim, "em um caso concreto, o princípio P1 tem um peso maior que o princípio colidente P2 se houver razões suficientes para que P1 prevaleça sobre P2 sob as condições C, presentes nesse caso concreto.” (ALEXY, 2015, p. 97).

Essa 'Lei de Colisão' "reflete a natureza dos princípios como mandamentos de otimização: em primeiro lugar, a inexistência de relação absoluta de precedência e, em segundo lugar, sua referência a ações e situações que não são quantificáveis”. (ALEXY, 2015, p. 99).

Alexy ressalta que uma colisão de princípios "será solucionada por meio de sopesamento, no qual nenhum dos princípios pode pretender uma precedência geral. Ao contrário, é necessário decidir qual interesse deve ceder, levando-se em consideração a configuração típica do caso e suas circunstâncias especiais”. (ALEXY, 2015, p. 100).

$\mathrm{O}$ autor destaca que "como resultado de todo sopesamento que seja correto do ponto de vista dos direitos fundamentais pode ser formulada uma 'norma de direito fundamental atribuída', que tem estrutura de uma regra e à qual o caso pode ser subsumido". (ALEXY, 2015, p. 102).

Para Alexy, um sopesamento é racional quando o enunciado de preferência pode ser fundamentado. "Com isso, o problema da racionalidade do sopesamento leva-nos à questão da possibilidade de fundamentação racional de enunciados que estabeleçam preferências condicionadas entre valores ou princípios colidentes". (ALEXY, 2015, p. 165).

Segundo Alexy, "a lei do sopesamento diz o que é importante no sopesamento: de um lado, o grau ou a intensidade da não-satisfação ou da afetação de um princípio e, de outro lado, o grau de importância da satisfação do outro princípio”. (ALEXY, 2015, p. 171).

Assim, o resultado do sopesamento é um "enunciado de preferências condicionadas", ao qual, de acordo com a lei de colisão, corresponde uma regra de decisão diferenciada. $\mathrm{O}$ modelo de sopesamento como um todo "oferece um critério, ao associar a lei de colisão à teoria da argumentação jurídica racional". (ALEXY, 2015, p. 173/174). 
A lei de colisão "demonstra que o sopesamento conduz a uma dogmática diferenciada dos diferentes direitos fundamentais: nos casos de colisão é necessário definir uma relação condicionada de preferência. A ela corresponde uma regra de grau de concretude relativamente alto". (ALEXY, 2015, p. 175).

Alexy conclui que o modelo de sopesamento "possibilita, de um lado, a satisfação das justificadas exigências de consideração das relações fáticas e das regularidades empíricas e de uma detalhada dogmática dos direitos fundamentais específicos; de outro lado, ele evita as dificuldades em torno da idéia de análise do âmbito da norma". (ALEXY, 2015, p. 175).

Para Marcelo Neves, os princípios constitucionais fortificam a capacidade de reprodução adequada do sistema jurídico, pois “os princípios são mecanismos reflexivos em relação às regras. Eles podem servir ao balizamento, à construção, ao desenvolvimento, à fortificação ou ao enfraquecimento, à restrição ou ampliação do conteúdo de regras". (NEVES, 2013, p. 131/132).

Marcelo Neves salienta que "os princípios constitucionais atuam como razão ou fundamento de regras, inclusive de regras constitucionais, nas controvérsias jurídicas complexas". (NEVES, 2013, p. 134).

De acordo com o autor, "há uma impossibilidade prática de aplicação imediata de princípios sem intermediação de regras, sejam estas legais ou constitucionais ou construídas jurisprudencialmente". (NEVES, 2013, p. 140).

Neves ainda ressalta que "a argumentação focada excessivamente em princípios constitucionais é sobremaneira falível, deixando amplo espaço para que se superem as próprias regras constitucionais desenvolvidas a partir dela”. (NEVES, 2013, p. 141).

Tomaz pondera que "princípios em colisão não se excluem, sujeitam-se antes à ponderação, critério balizador da função garantidora que, sem dúvida, possui o condão de afastar a originalidade da decisão judicial que não estaria criando direito retroativamente senão garantindo direito preexistente”. (TOMAZ, 2012, p. 246).

\subsection{A Ponderação de Princípios Colidentes}

Para Marcelo Neves (2013, p. 141), “não há dúvida de que a exigência de ponderação ou sopesamento em caso de colisão entre princípios constitucionais (e em geral entre normas) é inafastável". Contudo, o autor assevera que "não há garantia de sucesso e um modelo de 
ponderação otimizante é subcomplexo para enfrentar a delicada questão da colisão de princípios”. (Neves, 2013, p. 150).

Dworkin (2001, p. 15) destaca que "um juiz que segue a concepção do Estado de Direito centrada nos direitos tentará, num caso controverso, estruturar algum princípio que, para ele, capta, no nível adequado de abstração, os direitos morais das partes que são pertinentes às questões levantadas pelo caso". E é por isso que Tomaz aduz que "se o direito é uma ciência cultural, a decisão judicial há de ser construída no contexto sociopolítico-econômico, enfim, cultural, o que decorre da constatação de que o Estado constitucional se erige, precisa e depende de uma infraestrutura sociocultural”. (TOMAZ, 2012, p. 280).

Desta forma, a ponderação de princípios colidentes é uma das técnicas de argumentação e interpretação constitucional, que permite a comparação de diferentes perspectivas dos direitos fundamentais. Neste sentido, Marcelo Neves ensina que:

\footnotetext{
As questões constitucionais mais controversas, envolvendo princípios e regras, serão tratadas mais adequadamente em uma prática constitucional capaz de reagir aos perigos da desdiferenciação (no plano dos sistemas sociais e das ordens jurídicas entrelaçadas em torno de problemas constitucionais) e da negação da dupla contingência (no plano das pessoas e grupos). Isso exige que essa prática, ao absorver o dissenso em torno de princípios com a exclusão de perspectivas subjacentes a estes, seja capaz de reorientar e estabilizar as expectativas normativas correspondentes. (NEVES, 2013, p. 159).
}

O autor destaca que há possibilidade de colisões intraprincípios, ou seja, quando se parte da colisão envolvendo o mesmo princípio. Neste caso, "as leituras podem ser as mais diversas e os modelos argumentativos entre si incomensuráveis”. (NEVES, 2013, p. 160).

A questão da colisão intraprincípios ganha relevância quando se considera a diferenciação da sociedade em várias esferas de comunicação, pois "os princípios variam conforme a esfera de comunicação em que se aplicam". (NEVES, 2013, p. 162).

\section{A COLISÃO DOS DIREITOS FUNDAMENTAIS - DIREITO À VIDA E À LIBERDADE DE CRENÇA}

Marcelo Neves (2013, p. 165) salienta que “o direito fundamental à vida, enquanto fundado em princípio constitucional em concorrência com outros princípios, enseja conflitos entre diferentes compreensões de proteção à vida e o seu valor na respectiva ordem". 
Voltando ao caso da menina Juliana, Testemunha de Jeová, de São Vicente/SP, cabe destacar a compreensão manifestada no voto vencido no Recurso em sentido Estrito, do Desembargador Waldir Sebastião de Nuevo Campos Júnior, da $9^{a}$ Câmara Criminal do Tribunal de Justiça do Estado de São Paulo, ao consignar que "não há direito individual fundamental que comporte exercício absoluto, pois tal importaria em sobreposições, e consequentemente em anulações dos sobrepostos". (BRASIL, 2014, p. 21/22).

Sobre a colisão de direitos fundamentais existentes no caso em tela, o Desembargador Nuevo Campos salientou, em seu voto, que "a solução está na ponderação dos mandamentos em conflito, a partir da identificação das circunstâncias do caso concreto e seus reflexos na aplicação das normas colidentes, para verificação do ponto do equilíbrio indispensável à efetividade das disposições constitucionais incidentes no caso concreto". (BRASIL, 2014, p. 21/22).

Assim, o Desembargador Nuevo Campos concluiu que "o reconhecimento da necessidade de prevalência do direito à vida, consideradas as especificidades presentes, não importa, em absoluto, em negação da garantia constitucional concernente à liberdade religiosa, mas em solução indispensável para se tentar evitar a negação do direito à vida à ofendida". (BRASIL, 2014, p. 21/22). Recorde-se que para Alexy “um princípio restringe as possibilidades jurídicas de realização do outro. Essa situação não é resolvida com a declaração de invalidade de um dos princípios e com sua eliminação do ordenamento jurídico”. (ALEXY, 2015, p. 96).

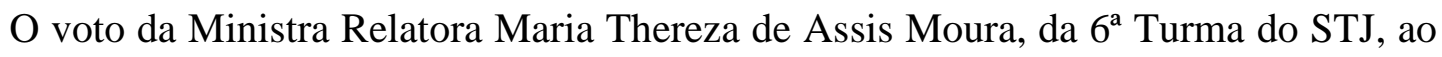
decidir o Habeas Corpus n 2 $^{\circ}$ 68.459-SP, asseverou que "ausente alternativa que pudesse tempestivamente colocar a vida da filha dos pacientes a salvo, impenderia aos médicos do hospital, passando por cima de qualquer obstáculo, materializar a intervenção que restasse". (BRASIL, 2014, p. 26). E concluiu em seu voto que, neste caso, "se falha houve, teria sido, penso, dos médicos responsáveis pela internação, que, ausente a possibilidade de profícuo tratamento alternativo, não cumpriram com o seu dever de salvar a adolescente, com a única terapia de que dispunham”. (BRASIL, 2014, p. 26/27).

Para fundamentar a sua decisão, a Ministra Relatora Maria Thereza de Assis Moura apontou normas constitucionais (artigo 227 da Carta Magna) e infraconstitucionais (artigo $7^{\circ}$ do Estatuto da Criança e do Adolescente). (BRASIL, 2014, p. 26/28).

A Relatora ainda consignou, em seu voto, que "o próprio Código Penal (inciso I do $\S$ $3^{\circ}$ do artigo 146) afasta a responsabilidade pelo emprego de violência ou grave ameaça, a fim 
de viabilizar intervenção médica ou cirúrgica, sem o consentimento do paciente ou de seu representante legal, se justificada por iminente perigo de vida”. (BRASIL, 2014, p. 26/28).

Neste mesmo sentido temos várias jurisprudências que autorizam a realização de transfusão de sangue em paciente da religião "Testemunhas de Jeová". Contudo, este posicionamento não é pacificado. A título de exemplo, permite-se citar o julgamento da Apelação Cível nº 132.720-4/9-00, realizado em 26.06.2003, pela $5^{\text {a }}$ Câmara de Direito Privado do Tribunal de Justiça de São Paulo, que, por voto unânime ${ }^{4}$, mantiveram a sentença de Ação Cautelar, da Comarca de Limeira/São Paulo, que autorizou a realização de transfusão de sangue em paciente da religião Testemunhas de Jeová. (SÃO PAULO, 2003, p. 1).

Este caso trata de vítima de um acidente automobilístico (Vivian Miranda D’Hipólito Paião), que foi internada na Unidade de Tratamento Intensivo da Santa Casa de Misericórdia de Limeira/SP, ocasião em que seu marido, Marcos Aparecido Paião (Apelante), alertou ser ela adepta da religião "Testemunhas de Jeová", apresentando um documento por ela subscrito, no qual há expressa recusa a tratamentos que impliquem em transfusão de sangue e seus derivados. (SÃO PAULO, 2003, p. 1/2).

Através de Ação Cautelar, a Santa Casa de Misericórdia de Limeira/SP requereu e obteve liminarmente autorização para a realização de transfusão de sangue na paciente. Sobreveio a sentença acolhendo em parte a pretensão para que, somente se necessário, se realize a transfusão de sangue. O marido da paciente apelou buscando reformar a sentença. (SÃO PAULO, 2003, p. 1/2).

No julgamento desta Apelação, o Desembargador Relator Boris KMJFFMANN destacou em seu voto que "o art. 5', VI, da Constituição Federal, assegura o direito à liberdade de consciência e de crença, bem como a inviolabilidade da intimidade e da vida privada. Com base nestas cláusulas é que o apelante defende o direito de sua esposa de recusar o tratamento com transfusão de sangue". Contudo, o Desembargador Relator asseverou que "não se pode negar, todavia, que os vários direitos previstos nos incisos do art. $5^{\circ}$ da Constituição Federal ostentam certa gradação em relação a outro direito, este estabelecido no caput do referido artigo: o direito à vida". (SÃO PAULO, 2003, p. 3/4).

\footnotetext{
4 "Ementa: Testemunhas de Jeová. Necessidade de transfusão de sangue, sob pena de risco de morte, segundo conclusão do médico que atende o paciente. Recusa dos familiares com apoio na liberdade de crença. Direito à vida que se sobrepõe aos demais direitos. Sentença autorizando a terapêutica recusada. Recurso desprovido". (SÃO PAULO, 2003, p. 1). (destaques nossos).
} 
Restou evidenciada a assertiva de Marcelo Neves (2013, p. 159) ao afirmar que "a ponderação de princípios colidentes é uma das técnicas de argumentação e interpretação constitucional, permitindo a comparação de diferentes perspectivas da Constituição e dos direitos fundamentais".

Permite-se, ainda, registrar outro caso. Trata-se do julgamento da Apelação $\mathrm{n}^{\circ}$ 0000460-26.2012.8.26.0629-3, realizado em 18.11.2014, pela 10ª Câmara de Direito Privado do Tribunal de Justiça de São Paulo, que por voto unânime ${ }^{5}$, mantiveram a sentença de Ação de Obrigação de Fazer e Não Fazer da Comarca de Tietê/São Paulo, que negou provimento ao pedido para que a Apelada (Associação Torre de Vigia de Bíblias e Tratados, igreja da religião Testemunhas de Jeová) se abstenha de estimular a discriminação em seus cultos religiosos, induzindo o afastamento dos familiares, namorado e amigos da Apelante (Amanda Vieira Costa). (SÃO PAULO, 2014, p. 2).

O caso decorre da expulsão da Apelante (Amanda Vieira Costa) dos quadros da Igreja Apelada, em razão de ter se submetido à transfusão de sangue para tratamento de "leucemia mieloide aguda", realizada mediante decisão judicial. A partir deste momento, os "Anciãos da Congregação" orientavam que os familiares e fiéis se afastassem dela, pois um fiel só pode se relacionar com quem tem a mesma crença. (SÃO PAULO, 2014, p. 2/4).

A Igreja Apelada nega que tenha orientado parentes ou amigos da Autora a não se relacionarem com ela, pois a doutrina é contra o fim dos laços familiares. Defende-se, ainda, que "a forma de desligamento de seus membros é matéria eminentemente de disciplina eclesiástica interna", sendo vedada a interferência do Estado. (SÃO PAULO, 2014, p. 4).

Neste caso, o Desembargador Relator concluiu, em seu voto, que "não pode o Estado intervir em matéria de fé, tampouco incentivar ou desestimular certas doutrinas em detrimento de outras. Portanto, em razão da não ingerência dogmática, deve o Estado se abster de qualquer comportamento valorativo de cunho religioso". (SÃO PAULO, 2014, p. 4/6).

\footnotetext{
5 "Ementa: NULIDADE - Cerceamento de defesa - Julgamento antecipado da lide - Presença dos requisitos do artigo 458 do Código de Processo Civil - Possibilidade do juiz dispensar a produção de provas - Princípio do livre convencimento motivado - Aplicação do art. 330, inciso I, do Código de Processo Civil - Preliminar rejeitada. OBRIGAÇÃO DE FAZER E NÃO FAZER - Inviolabilidade da liberdade de consciência e de crença (artigo $5^{\circ}$, inciso VI, da Constituição Federal) - Autora praticante da religião Testemunhas de Jeová e submetida à transfusão sanguínea - Alegada discriminação religiosa e social - Quebra do mandamento doutrinário - Desassociação (exclusão) de membro - Vedação da interferência estatal nos atos interna corporis das organizações religiosas Pretensão da autora para que a ré se abstenha de proibir o seu convício social com familiares, amigos, fiéis ou ex-fiéis - Ausente comprovação de conduta ameaçadora por parte da ré e exposição da autora a constrangimento ou humilhação - Sentença mantida - RECURSO NÃO PROVIDO.” (SÃO PAULO, 2014, p. 2). (destaques nossos).
} 
Cabe destacar que o caso da Amanda Vieira Costa (Tietê/SP), no primeiro momento, relata a colisão entre o Direito à Vida e a Liberdade de Consciência e de Crença (quando a autora, Testemunha de Jeová, necessitou de transfusão de sangue em função do agravamento da sua moléstia); e, no segundo momento, a colisão entre a Liberdade de Consciência e de Crença e a Dignidade da Pessoa Humana (quando da sua expulsão dos quadros da Igreja Apelada em razão da transfusão de sangue e pela discriminação nos cultos religiosos, induzindo o afastamento dos familiares, namorado e amigos). (SÃO PAULO, 2014, p. 4/6).

Ressalte-se, neste caso, que o Desembargador Relator Elcio Trujillo apontou em seu voto o caráter principiológico dos direitos fundamentais que eventualmente se colidem e aduziu para a solução ponderada, através da "técnica da ponderação" (adotada por Robert Alexy em sua obra Teoria dos Direitos Fundamentais), apoiando-se, essencialmente, no postulado da proporcionalidade. (SÃO PAULO, 2014, p. 4/6).

A este respeito, Neves (2013, p. 165) assevera que "o direito fundamental à vida, enquanto fundado em princípio constitucional em concorrência com outros princípios, enseja conflitos entre diferentes compreensões de proteção à vida e o seu valor na respectiva ordem".

A complexidade desta assertiva é ilustrada pelo autor através da colisão entre a ordem jurídica estatal brasileira e a ordem normativa dos índios Suruahá , pois “conforme o direito consuetudinário dos Suruahá é obrigatório o homicídio dos recém-nascidos quando tenham alguma deficiência física ou de saúde em geral”. (NEVES, 2013, p. 166).

Neves (2013, p. 166) relata outra realidade envolvendo os indígenas Yawanawa, localizados no Estado do Acre, fronteira entre Brasil e Peru, onde "há uma ordem normativa consuetudinária que determina que se tire a vida de um dos gêmeos recém-nascidos”.

$\mathrm{O}$ autor ainda pondera que "o desafio decisivo que se apresenta ao órgão de interpretação - aplicação constitucional nos casos de colisões intraprincípios e interprincípios é de como reorientar as expectativas normativas dos envolvidos diretamente e indiretamente na respectiva controvérsia". (NEVES, 2013, p. 169).

\section{CONSIDERAÇÕES FINAIS}

\footnotetext{
${ }^{6}$ Habitantes do Município de Tapauá, no Estado do Amazonas, que permaneceram isolados voluntariamente até os fins da década de 1970. (NEVES, 2013, p. 166).
} 
Como verificado, a ponderação de princípios colidentes é uma das técnicas de argumentação e interpretação constitucional, permitindo a comparação de diferentes perspectivas da Constituição e dos direitos fundamentais. O presente trabalho baseou-se na premissa de que os princípios ordenam que algo seja realizado, na maior medida possível, dentro das possibilidades jurídicas e fáticas existentes.

No caso da menina Juliana Bonfim da Silva (São Vicente/SP) cabe destacar que o reconhecimento da necessidade de prevalência do direito à vida da menor não representou em negação da garantia constitucional da liberdade religiosa, mas, tão somente, em solução indispensável para se evitar a negação do seu inviolável direito à vida.

No caso da Amanda Vieira Costa (Tietê/São Paulo) verifica-se que houve a colisão entre o direito à vida e a liberdade de crença (quando a autora, Testemunha de Jeová, realizou a transfusão de sangue) e, no segundo momento, a colisão entre a liberdade de crença e a dignidade da pessoa humana (quando foi expulsa da Igreja Apelada em função da transfusão de sangue e na discriminação nos cultos religiosos, induzindo o afastamento dos familiares, namorado e amigos) Este caso retrata que o direito à vida não se resume ao viver. $\mathrm{O}$ direito à vida diz respeito ao modo de viver, a dignidade do viver da pessoa, levando-se em consideração seus valores morais, éticos e religiosos. Por outro lado, a ponderação entre a liberdade de crença e a dignidade da pessoa humana não foi erigida a ponto de excluir uma em detrimento de outra, na exata medida que o Poder Judiciário não se imiscuiu na liberdade de crença, dado o caráter laico do Estado brasileiro, diante de circunstâncias que impelem assegurar, igualmente, o respeito aos valores morais e éticos de cada religião.

Assim, constata-se que a ponderação dos princípios deve ser determinada através da análise das circunstâncias e especificidades de cada caso concreto, devidamente fundamentada em elementos contextuais. Em caso de conflitos entre regras, o resultado de sua equalização será uma determinação da validade de uma regra sobre a outra. Já no caso dos princípios, a prevalência de um sobre o outro, em um caso concreto, não implica seu afastamento definitivo para outros casos.

Voltando ao caso Amanda Vieira Costa, constata-se que o método da ponderação ao invés de "relativizar os direitos fundamentais" em casos de colisão, os tornam mais fortes quando são ponderados, demonstrando que possuem um núcleo resistente que permanecerá nos casos de colisão. E é esse núcleo, aliado ao contexto, que constituem substratos da compreensão voltada para o alcance de uma resposta corretamente justificada. 
É por isso que a adequação social do direito significa a capacidade de possibilitar a convivência não destrutiva de diversos projetos e perspectivas. E nesse caminho, os des(acordos) encontram-se plantados em questões morais altamente complexas e as respostas sempre de difícil alcance. Tenha-se presente, todavia, que o fiel da balança a dignidade do homem, o homem humano do direito, que deve ser o seu projeto e a partir do qual qualquer interlocução deve ser alçada.

\section{REFERÊNCIAS}

ABBAGnANO, Nicola. Dicionário de filosofia. São Paulo: Martins Fontes, 2007.

ALEXY, Robert. Sistema jurídico, principios jurídicos y razón práctica. Doxa, Barcelona, $\quad$ n.5, $1988 . \quad$ Disponível em: <http://www.cervantesvirtual.com/servlet/SirveObras/1247173098

2570739687891/cuaderno5/Doxa5_07.pdf>.

ALEXY, Robert. Teoria dos Direitos Fundamentais. Trad. SILVA, Virgílio Afonso da. $2^{\mathrm{a}}$ ed. $4^{\mathrm{a}}$ tiragem. São Paulo: Malheiros, 2015.

BRASIL, 2013. Constituição da República Federativa do Brasil de 1988. 48. ed. São Paulo: Saraiva, 2013.

BRASIL, 2014. Superior Tribunal de Justiça. Acórdão do Habeas Corpus $n^{\circ} 268.459$. Disponível em: <https://ww2.stj.jus.br/processo/revista/documento/mediado/?componente= ATC\&sequencial $=38540079 \&$ num_registro $=201301061165 \&$ data $=20141028 \&$ tipo $=$ $5 \&$ formato $=\mathrm{PDF}>$.

DWORKIN, Ronald. Uma questão de princípios. São Paulo: Martins Fontes, 2001.

DWORKIN, Ronald. Levando os Direitos a Sério. Trad. BOEIRA, Nelson. São Paulo: Martins Fontes, 2002. 
JW.ORG. Site Oficial das Testemunhas de Jeová, ( 2015). Disponível em: $<$ https://www.jw.

org/pt/testemunhas-de-jeova/perguntas-frequentes/por-que-testemunhas-jeova-naotransfusao-sangue/>.

JW.ORG(2016). Revista Despertai! fev. 2016. vol. 97, n 1. Publicação da Associação Torre de Vigia de Bíblias e Tratados. São Paulo: JW.ORG, 2016.

NEVES, Marcelo. Entre Hidra e Hércules: princípios e regras constitucionais como diferença paradoxal do sistema jurídico. São Paulo: WMF Martins Fontes, 2013.

SÃO PAULO, 2003. Tribunal de Justiça do Estado de São Paulo. Acórdão de Apelação Cível $\quad \mathrm{n}^{\circ} \quad$ 132.720-4/9-00. Disponível em: <https://esaj.tjsp.jus.br/cjsg/resultadoSimples.do?nuProcOrigem=132.720-4\%2F900\&nuRegistro $=>$.

SÃO PAULO, 2010. Tribunal de Justiça do Estado de São Paulo. Acórdão do Recurso sentido Estrito $n^{o}$ 993.99.085354-0, Disponível em: $<$ https://esaj.tjsp.jus.br/pastadigital/abrirDocumentoEdt.do?origemDocumento=A\&nuProcess $\mathrm{o}=000033897.1993 .8 \cdot 26.0590 \& \mathrm{cdProcesso}=\mathrm{RL}$ 000A08J0000\&cdForo=990\&tpOrigem $=2 \& \mathrm{fl}$ Origem $=$ S\&nmAlias=SG5SP $\&$ cdServico $=190201 \&$ ticket $=f D p \% 2 B i 94 R Z h 5$ fopwTZCljnTbD mGLf\%2FMwTyeWqRiDkbRiCy4IUZbNOKN4F0x YudKlvDXASMuB3YJcpJGCbfhr7t301 dlp92\%2BGHI0iHgKWVoS2vkQg\%2Fd2Uzp\%2BGny\%2BKR\%2BYOwTWXptQignWFJc h18b0slhUkWVNbBFtjt2OPqM2mm06C6tTaL4M\%2Fh9ESxGbmWYBKtiZTp615ukmEdjk xWVj9rCr1NjHy9fPVNcTB3fy6kIc0\%3D>.

SÃO PAULO, 2014. Tribunal de Justiça do Estado de São Paulo. Acórdão de Apelação Cível $n^{o}$ 0000460-26.2012.8.26.0629, Disponível em: <https://esaj.tjsp.jus.br/cjsg/resultado Simples.do?nuProcOrigem=0000460-26.2012.8.26.0629\&nuRegistro=>.

TOMAZ, Carlos Alberto Simões de. Democracia e jurisdição: entre o texto e o contexto. $1^{a}$. ed. São Paulo: Baraúna, 2012. 